\title{
Ex Vivo Gene Therapy: A “Cultured" Surgical Approach to Curing Inherited Liver Disease
}

\author{
Caitlin J VanLith ${ }^{1}$, Robert A Kaiser ${ }^{1,2}$, Clara T Nicolas ${ }^{1}$ and Joseph B Lillegard ${ }^{1,2,3 *}$ \\ ${ }^{1}$ Department of Surgery, Mayo Clinic, Rochester, MN, USA \\ ${ }^{2}$ Midwest Fetal Care Center, Children's Hospital of Minnesota, Minneapolis, MN, USA \\ ${ }^{3}$ Pediatric Surgical Associates, Minneapolis, MN, USA
}

Received: February 22, 2019; Published: March 21, 2019

*Corresponding author: Joseph B Lillegard, Midwest Fetal Care Center, Children's Hospital of Minnesota, Minneapolis, Minnesota, USA and Mayo Clinic, Rochester, Minnesota, USA

\section{Introduction}

Inborn errors of metabolism (IEMs) are a group of inherited diseases caused by mutations in a single gene [1], many of which are identified in Table 1 . Though individually rare, combined incidence is about 1 in 1,000 live births [2]. While maintenance therapies exist for some of these liver-related diseases, Table 1: List of 35 of the most common Inborn Errors of Metabolism.

\begin{tabular}{|c|c|}
\hline Inborn Error of Metabolism & Abbreviation \\
\hline Hereditary Tyrosinemia type 1 & HT1 \\
\hline Wilson Disease & Wilson \\
\hline Glycogen Storage Disease 1 & GSD1 \\
\hline Carnitine Palmitoyl Transferase Deficiency Type 2 & СРT2 \\
\hline Glycogen Storage Disease 4 & GSD4 \\
\hline Citrullinemia Type 2 & Cit2 \\
\hline Congenital Erythropoietic Porphyria & CEP \\
\hline Propionic Acidemia & $\mathrm{PA}$ \\
\hline Gaucher Disease & Gaucher \\
\hline Phenylketonuria & PKU \\
\hline Hemophilia B & Hemo \\
\hline Trans aldolase Deficiency & Transaldo \\
\hline $\begin{array}{l}\text { Citrullinemia Type } 1 \\
\text { aka Arginosuccinate Synthetase Deficiency }\end{array}$ & Cit1 \\
\hline Niemann-Pick C Disease Type D & NPC \\
\hline Primary Oxalosis & PHO \\
\hline Methylmalonic Acidemia (Mut0 Type) & MMA \\
\hline Amyloidosis & Amyl \\
\hline Congenital Disorder of Glycosylation Type $1 \mathrm{~A}$ & CDG $1 \mathrm{~A}$ \\
\hline Maple-Syrup-Urine Disease & MSUD \\
\hline Galactosemia type 1 & Gal1 \\
\hline Medium Acyl CoA Dehydrogenase Deficiency & MCAD \\
\hline Carbamoyl Phosphate Synthetase Deficiency & CPS1 \\
\hline Ornithine Transcarbamylase Deficiency & OTC \\
\hline
\end{tabular}

transplant remains the only curative option. Between 1988 and $2018,12.8 \%$ of 17,009 pediatric liver transplants in the United States were primarily due to an inherited liver disease.

(see www.optn.transplant.hrsa.gov/data/). 


\section{Open Access Journal of Surgery}

\begin{tabular}{|c|c|}
\hline Isovaleric Acidemia & IVA \\
\hline Variegate Porphyria & VP \\
\hline Crigler-Najjar Syndrome type 1 & CNS1 \\
\hline Alpha-1-Anti-Trypsin Deficiency & LCHAD \\
\hline Long Chain Hydroxy Acyl CoA Dehydrogenase Deficiency & Fam Hyp \\
\hline Familial Hypercholesterolemia, homozygous & AIP \\
\hline Acute Intermittent Porphyria & PCT2 \\
\hline Porphyria Cutanea Tarda Type 2 & IRD \\
\hline Infantile Refsum Disease & Mito PolG \\
\hline Mitochondrial Disorders (including PolG Deficiency) & HCP \\
\hline Hereditary Coproporphyria & VLCAD \\
\hline
\end{tabular}

From a gene therapy standpoint, we believe viewing IEM of the liver collectively allows for thoughtful overlapping approaches to solving these disorders based on disease characteristics and etiology, which ultimately play a role in defining potential barriers to gene therapy treatment. All IEMs can be thought of as existing within a gene therapy Venn diagram based on

i. Presence of a positive selective advantage for corrected cells

ii. Liver-centric vs. systemic phenotype of the disease

iii. Immunologic consequences of correction, such as with extracellular/secreted novel gene products (Figure 1).

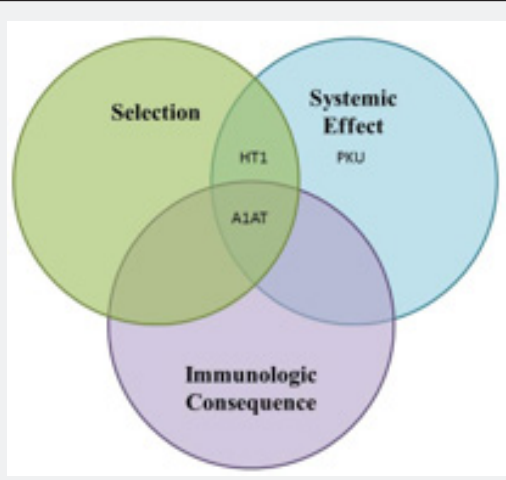

Figure 1 : IEMs of the liver can be contemplated in a Venn diagram based on three considerations, positive selection for corrected cells, presence of systemic effects of the disease, and potential for immunologic consequence of introducing a corrected gene. Representative diseases HT1, PKU and AAT are plotted as examples.

Hereditary tyrosinemia type I (HT1) is representative of one such disorder and may possibly represent the most approachable disease with regards to gene therapy. HT1 results from a deficiency of the intracellular enzyme, fumarylacetoacetate hydrolase [3], preventing the complete metabolism of the essential amino acid tyrosine. Untreated, this leads to the buildup of hepatotoxic metabolites that severely injure hepatocytes (HC) leading to inflammation, fibrosis, cirrhosis and liver failure [4]. The HT1 phenotype leads to a strong positive selective advantage for HCs treated via gene therapy [5]. Corrected HCs will grow and expand at the expense of untreated injured HCs. With the tremendous selective pressure of the disease phenotype and the substantial regenerative capacity of the liver, correction of $1 \%$ of HCs can lead to near total repopulation of the liver with corrected HCs in months as is seen in small and large animal models of HT1 [6]. The presence of phenotypes outside of the liver completes assignment of HT1 to the overlap of Selection and Systemic Effects in Figure 1.

Phenylketonuria (PKU) is representative of another type of IEMs of the liver. In PKU, HCs cannot undergo the first step of phenylalanine metabolism because of a lack of phenylalanine hydroxylase (PAH). PAH is an intracellular $\mathrm{HC}$ enzyme and when absent leads to significant elevation of phenylalanine in the blood, which causes seizures, delayed physical and neurocognitive development, behavioral problems, psychiatric disorders and eczema. Notably, the toxic effects of elevated serum phenylalanine are found primarily outside of the liver while the liver is largely unaffected by the disease. Therefore, there is no positive selection for corrected HCs as is seen in HT1, and PKU exists in a separate section of the diagram.

Finally, alpha-1 antitrypsin deficiency (A1AT) represents another subtype of IEMs of the liver. A1AT is a group of diseases caused by a mutation in the SERPINA1 gene, which leads to a build of the A1AT protein in HCs and unopposed neutrophil elastase activity in the lung. A1AT is a protein normally secreted by HC. In A1AT deficiency the protein is not properly secreted and builds up in HCs that can cause severe liver injury. Gene therapy for a protein product that is not present during negative T-cell selection in utero and does not remain intracellular represents a potential immunological consequence to the novel protein when gene therapy is applied.

All IEMs of the liver can be described in a specific region of the diagram in this paradigm. This proper understanding of disease pathophysiology is important for development of effective cures for each classification of disease. 


\section{Current Therapies}

Current treatments for IEMs of the liver include lifestyle alterations, small molecules, cofactors and vitamins, and enzyme replacement therapy. For example, avoiding foods that contain phenylalanine (in PKU and HT1) or tyrosine (in HT1) helps delay disease progression. However, patient compliance presents a challenge to these diets, and they can include expensive alternative foods, causing an additional burden for families. Often, damage at the cellular level can be irreversible, and many diseases will continue to progress to cell death and organ failure, though on a longer timescale with dietary changes.

The sensitivity of some diseases to vitamin or cofactor supplementation can be at the mercy of the specific genetic mutation in the patient. For example, patients with PKU will often be compound heterozygotes at the Pah locus (harboring 2 different PKU-inducing alleles), and they will exhibit the phenotype driven by the least severe of those alleles. If at least one allele has partial activity, it may be augmented by supplementation with the cofactor tetrahydrobiopterin, forcing enzyme kinetics toward healthy phenylalanine metabolism. However, efficacy of this approach will show high variation between patients with different mutant alleles.

Currently, the ideal treatment for these diseases is a small molecule maintenance regimen. In one of the beststudied examples, 2-(2-nitro-4-trifluoromethylbenzoyl)-1,3cyclohexanedione (NTBC, aka nitisinone and marketed as Orfadin) was hailed as a breakthrough for HT1 patients when it became available in the 1990s. NTBC prevents the early severe HT1 phenotype (liver fibrosis, cirrhosis, and hepatocellular carcinoma) by disrupting tyrosine catabolism earlier in its breakdown - at 4 hydroxyphenylpyruvate dioxygenase (HPD) which prevents the buildup of some of the more toxic tyrosine metabolites and induces hereditary Tyrosinemia type III (HT3). There is no doubt that this intervention has improved and saved the lives of many HT1 patients, primarily by reducing acute prevalence of hepatocellular carcinoma. However, a trade-off is created in switching HT1 for HT3. That problem is two-fold:

i. HT3 is not without consequence on its patients. The disease carries its own symptom burden, and

ii. As more becomes known about NTBC, it is becoming more apparent those patients display significant progressive cognitive and ocular impairment $[7,8]$.

Additionally, accounts are becoming available that demonstrate that patients on NTBC can still progress to HCC [9]. Finally, the cost of NTBC is roughly $\$ 300 / 10 \mathrm{mg}$ capsule (see www.drugbank.ca). Therefore, the effective dose of up to 2 $\mathrm{mg} / \mathrm{kg} /$ day would cost the family of a $20 \mathrm{~kg}$ child approximately $\$ 1200 /$ day. Even initially expensive alternatives become financially viable in the context of such cost, especially ones that offer improved outcomes.
Currently, all these available treatments share a common trait: they fall short of a true cure. Although some of these diseases can be cured via liver allotransplantation, there is a severe shortage of donor organs and the consequences of the transplantation procedure itself, along with the immunosuppression it entails, provide lifelong implications for the patient.

\section{Ex vivo Gene Therapy for Liver Metabolic Disease}

Gene therapy offers these patients a real chance at a true cure. As described in the literature, diseased HCs are collected from the patient via laparoscopic partial hepatic resection. Those HCs are then cultured ex vivo, where they undergo gene therapy (delivery or correction) and are transplanted back into the patient via ultrasound-guided portal vein perfusion [10]. In recent studies, a single ex vivo gene therapy procedure with a lentiviral vector expressing human $F A H$ has been demonstrated to cure mouse and pig models of HT1 for the duration of their lives $[6,11]$. Although some development has gone into disrupting Hpd using gene editing [12] this approach results in patients with two genetic mutations (one inherited and one iatrogenic) that still result in elevated tyrosine levels and effects of both HT1 and HT3. Worse, it would invalidate them from a subsequent curative gene delivery trial with $F A H$, because tyrosine metabolism would largely stop upstream at the disrupted HPD, not progressing to FAH to complete the pathway.

IEMs such as HT1 provide a straightforward path to cure with ex vivo gene therapy. Therapy becomes more difficult when considering diseases that confer less of a selective advantage to corrected HCs or introduce potential for immune responses due to presentation of novel antigenic proteins. Though recent evidence suggests that corrected HCs in an A1AT model do show a modest selective advantage [13], other diseases affecting extracellular/secreted proteins may not. Work instead must focus on getting enough initial transduction of target cells to show a phenotypic change in the levels of protein expressed and trafficked. Likewise, diseases in the PKU category lack any selective advantage. Work is being done to engineer an artificial selective advantage for treated HCs [14]. Clever workarounds like these might be the solution to treat all diseases that fall within our view of the IEM paradigm.

To be sure, ex vivo gene therapy is neither simple nor inexpensive. However, the potential to provide patients with a single procedure that results in actual cure of the disease is worth the invasiveness of the initial autologous hepatocyte harvest and the subsequent auto transplantation of the corrected cells. The quality and quantity of life these patients would enjoy would more than justify the cost and involvement of the intervention, especially when mitigated as the difference in cost relative to a lifetime on an expensive maintenance drug and surveillance program.

\section{References}

1. Hansen K, S Horslen (2008) Metabolic liver disease in children. Liver Transpl 14(5): 713-33. 
2. Jalan AB (2014) Treatment of inborn errors of metabolism. Mol Cytogenet 7: I42.

3. Lindblad B, S Lindstedt, G Steen (1977) On the enzymic defects in hereditary tyrosinemia. Proc Natl Acad Sci 74(10): 4641-4645.

4. Gentz, J, R Jagenburg, R Zetterstroem (1965) Tyrosinemia. J Pediatr 66: 670-696.

5. Overturf K (1996) Hepatocytes corrected by gene therapy are selected in vivo in a murine model of hereditary tyrosinaemia type I. Nat Genet 12(3): 266-273.

6. Hickey RD (2016) Curative ex vivo liver-directed gene therapy in a pig model of hereditary tyrosinemia type 1 . Sci Transl Med 8(349): 349399.

7. Thimm E (2012) Neurocognitive outcome in patients with hypertyrosinemia type I after long-term treatment with NTBC. J Inherit Metab Dis 35(2): 263-268.

8. Bendadi $F$ (2014) Impaired cognitive functioning in patients with tyrosinemia type I receiving nitisinone. J Pediatr 164(2): 398-401.
9. van Spronsen FJ (2005) Hepatocellular carcinoma in hereditary tyrosinemia type I despite 2-(2 nitro-4-3 trifluoro- methylbenzoyl)-1, 3-cyclohexanedione treatment. J Pediatr Gastroenterol Nutr 40(1): 9093.

10. Kaiser RA (2018) Lentiviral Vector-mediated Gene Therapy of Hepatocytes Ex Vivo for Autologous Transplantation in Swine. J Vis Exp 4: 141 .

11. Hickey RD (2018) Autologous Gene and Cell Therapy Provides Safe and Long-Term Curative Therapy in A Large Pig Model of Hereditary Tyrosinemia Type 1. Cell Transplant 28(1): 79-88.

12. Rossidis AC (2018) In utero CRISPR-mediated therapeutic editing of metabolic genes. Nat Med 24(10): 1513-1518.

13. Borel F (2017) Survival Advantage of Both Human Hepatocyte Xenografts and Genome-Edited Hepatocytes for Treatment of alpha-1 Antitrypsin Deficiency. Mol Ther 25(11): 2477-2489.

14. Nygaard S (2016) A universal system to select gene-modified hepatocytes in vivo. Sci Transl Med 8(342): 342-379.

\section{Your next submission with Juniper Publishers will reach you the below assets}

- Quality Editorial service

- Swift Peer Review

- Reprints availability

- E-prints Service

- Manuscript Podcast for convenient understanding

- Global attainment for your research

- Manuscript accessibility in different formats

( Pdf, E-pub, Full Text, Audio)

- Unceasing customer service

Track the below URL for one-step submission https://juniperpublishers.com/online-submission.php 